\title{
MUJERES Y ACCIÓN POLÍTICA EN LA ANTIGUA ROMA. LECTURAS DE ETTORE CICCOTTI, UN SOCIALISTA EN LA EUROPA DEL SIGLO XIX*
}

\author{
WOMEN AND POLITICAL ACTION IN ANCIENT ROME. \\ READINGS OF ETTORE CICCOTTI, A SOCIALIST \\ IN NINETEENTH-CENTURY EUROPE
}

\author{
Rosa María Cid López** \\ Universidad de Oviedo
}

\begin{abstract}
RESUMEN. Entre las diferentes luchas sociales del siglo xIx, destaca la feminista, por su impacto entre los políticos e intelectuales de la época. Muchos pensadores la criticaron, pero otros defendieron los movimientos de liberación de las mujeres. Muy llamativo fue el caso de Ettore Ciccotti (1863-1939) político del Partido Socialista Italiano y profesor de Historia Antigua. Este historiador se inspira en los hechos protagonizados por las matronas romanas, sobre todo en los dos últimos siglos de la República, para reflexionar sobre el alcance de las actividades políticas de las mujeres en su época. Y lo hace como un hombre inmerso en el contexto político e historiográfico de la Italia de su tiempo. A pesar de su compromiso político, sus imágenes de las antiguas romanas no se sustraen a los prejuicios androcéntricos que predominaron en la Europa decimonónica. De su curiosa obra Donne e política negli ultimi anni della repubblica romana (1895), el contexto en que se publicó y su posterior influencia en los inicios de la historia de las mujeres se trata en este texto.

PALABRAS CLAVE: Matronas, República romana, Ettore Ciccotti, socialismo, feminismo, siglo XIX.

ABSTRACT. Among the various struggles of the 19th century, the feminist stands out, which had an impact in the politicians and intellectuals of the time. Many thinkers criticized feminist attitudes, while others supported women's liberation movements. Particularly striking was the case of Ettore Ciccotti (1863-1939), a politician of the Italian Socialist Party and a professor of Ancient History. This historian was inspired by the events carried out by the Roman matrons, especially in the last two centuries of the Roman Republic, to reflect on the scope of women's political activities. He does so as a man immersed in the political and historiographical context of the Italy of his time. Despite his political commitment, his understanding of Roman women still conforms to the androcentric prejudices that prevailed in 19th century Europe. This paper deals with his curious work Donne e politica negli ultimi anni della Repubblica romana (1895), the context in which it was published and its subsequent influence in the beginnings of the history of women.
\end{abstract}

KEYWORDS: Midwives, Roman republic, Ettore Cicotti, socialism, feminism, 19th century.

* Este texto se relaciona con el proyecto de I +D del Ministerio de Economía y Competitividad, titulado, Maternidades, filiaciones y sentimientos en las sociedades griega y romana de la antigüedad. Familias alternativas y otras relaciones de parentesco fuera de la norma (Ref. HAR2017-82521P).

** Correspondencia a / Correspondence to: Rosa María Cid López, Grupo Deméter, Área de Historia Antigua, Departamento de Historia, Campus de Humanidades, avda. Amparo Pedregal, s/n, Universidad de Oviedo (33011 Oviedo) - rcid@uniovi.es - https://orcid.org/0000-0002-8865-6738.

Cómo citar / How to cite: Cid López, Rosa María (2020), «Mujeres y acción política en la antigua Roma. Lecturas de Ettore Ciccotti, un socialista en la Europa del siglo XIX», Veleia, 37, 235-252. (https://doi.org/10.1387/veleia.20784).

Recibido: 2 marzo 2020; aceptado: 10 marzo 2020.

ISSN 0213-2095 - eISSN 2444-3565 / (C) 2020 UPV/EHU 
Desde sus más tempranos orígenes, la sociedad romana nos ofrece ejemplos de mujeres que destacaron en determinados episodios notables de su historia. Las primeras conocidas son casi siempre figuras legendarias, pero a medida que avanzamos en el tiempo, los mitos se desvanecen o van desapareciendo, y dan paso a figuras históricas femeninas que, a título individual o colectivo, se inmiscuyeron en la vida política. En general, lo hicieron para defender los intereses de la res publica o del Imperio y, habitualmente, para reforzar decisiones de varones que consolidaban modelos sociales defensores de los privilegios masculinos; pero, a veces y aunque de manera excepcional, los cuestionaron. Sin duda, las formas femeninas de "hacer política» diferían de los modos masculinos, ya que las matronas romanas idearon también sus propias estrategias. Por ello, sus actitudes resultaron sorprendentes tanto para sus coetáneos como para los intelectuales e historiadores de etapas más recientes, del siglo XviII al xx.

En cualquier caso, los ejemplos más llamativos de acciones políticas de las romanas, en lo que tienen de subversión, se observan en la República, sobre todo en sus fases finales. Si bien, conviene matizar el alcance de esta transgresión, que podía revelarse a través de las manifestaciones y protestas en la calle, la introducción y difusión de la superstitio en la religión romana o la conspiración en la domus. Aquellas mujeres practicaban lo que puede considerarse un poder femenino, aunque sin llegar a ejercer un cargo público o participar en los ámbitos institucionales; como es sabido, tales actividades resultaban inaccesibles para las ciudadanas romanas, salvo la excepción del desempeño de tareas sacerdotales, como ocurrió con las Vestales.

Al margen de lo sucedido en la antigua Roma, en la sociedad contemporánea este poder femenino no siempre, o casi nunca, fue bien visto, no solo por los defensores de un orden androcéntrico, sino incluso por quienes sostenían posturas ideológicas más avanzadas. Si la centuria decimonónica en Europa y EEUU fue aquella en la que emergieron el primer feminismo y el pensamiento socialista, con claro afán de promover cambios sociales radicales, también se llevaron a cabo transformaciones profundas en la concepción teórica y metodológica del estudio del pasado. En este sentido, merece la pena considerar cómo percibieron las biografías y los hechos que protagonizaron las matronas de la etapa final de la República en la Europa del siglo xIx, dada la evolución que estaba experimentando la posición social de algunas mujeres; especial relevancia adquieren las valoraciones sobre el poder femenino a partir de las actividades de las ciudadanas romanas, inmersas en los avatares políticos del último siglo a.C.

De los juicios sobre tales actitudes de las antiguas romanas, sobresalen los emitidos por Ettore Ciccotti, quien en 1895 publicó un estudio precisamente sobre las matronas de la República, partiendo de su posición de socialista, inmerso en las luchas y debates políticos decimonónicos. Me refiero a su obra Donne e politica negli ultimi anni della Repubblica romana ${ }^{1}$. Aunque la primera impresión puede ser que pretendía una reivindicación socialista, e incluso feminista, la versión perceptible en su obra, como sucede con la de otros intelectuales de su tiempo, igualmente marxistas, poco tiene que ver con una lectura crítica de la sociedad tradicional. Para explicar las razones por las que este historiador italiano se interesó por las matronas romanas, previamente evocaré los episodios que se les atribuyen, mencionando los nombres femeninos más notables; luego analizaré de qué modo nos las presenta el estudioso del Mezzogiorno italiano, en cuya percepción podría haber influido el feminismo decimonónico, más en vertiente socialista que sufragista o

1 Esta obra se publicó por primera vez en Italia en 1895. Con ocasión de su reimpresión, en 1985, Eva Cantarella elaboró un interesante texto introductorio, con información sobre la compleja personalidad de E.
Ciccotti; a la vez resaltaba la importancia de algunas feministas de Milán, cuya influencia traspasó las fronteras italianas (Cantarella 1985, VII-XXI). 
burguesa. Pero lamentablemente su formación socialista no parece haber marcado su valoración de las acciones políticas realizadas por las antiguas romanas, y tampoco se detecta una vinculación con el movimiento feminista, tan activo en el contexto de la sociedad italiana, sobre todo milanesa, que él debió conocer bien.

\section{La República romana y las acciones políticas de las mujeres. De la calle al templo Y DE LA DOMUS AL FORO}

Los nombres de Hersilia, Lucrecia o Virginia, entre otros, están ligados a grandes momentos de la primitiva Roma, aunque la historicidad de los episodios que se les atribuyen no resultan fáciles de demostrar; ante todo, destacan por su defensa de los intereses de la ciudad y de los varones, aunque solo en situaciones extraordinarias y sin cuestionar la autoridad masculina ${ }^{2}$. La situación cambia a partir del siglo ir a.C. y aún más en el siglo i a.C. No hace falta recordar aquí hasta qué punto la conquista del Mediterráneo alteró la sociedad romana, incluidas las relaciones de género, de modo que muchas mujeres lograron inmensas fortunas, además de conocimientos y gustos más refinados, de tinte helenizante. Este nuevo ambiente hizo que algunas rompieran con las tradiciones que las relegaban a los ambientes domésticos, de modo que empezaron a interesarse por los asuntos de la res publica. Ciertamente de la admiración de las primeras y dóciles matronas se pasa a la crítica de las segundas, las rompedoras con el mos maiorum, por su abandono de la domesticidad. En cualquier caso, resulta incuestionable el hecho de que algunos personajes femeninos se involucraron en las actividades políticas, hasta ese momento patrimonio exclusivo de la población masculina que disfrutaba de los derechos de ciudadanía ${ }^{3}$.

De los acontecimientos protagonizados por las romanas, resulta llamativo, y no parece que haya sido convenientemente resaltado entre especialistas de historia de Roma o de la historia de las mujeres y de género, el hecho de que una de las primeras manifestaciones públicas femeninas por las calles de la ciudad para exigir la derogación de una ley sucedió en los comienzos del siglo II a.C. ${ }^{4}$ Como es sabido, la acción matronal tuvo éxito y consiguieron su anulación.

Muy brevemente, lo acaecido, según el relato de Tito Livio (34.1), se relaciona con la Segunda Guerra Púnica, en la que se promulgó la lex Oppia, concretamente en el año 215 a.C., momento coincidente con una situación de graves peligros por las amenazas externas ${ }^{5}$. Mediante esta norma, se prohibía a las mujeres la exhibición de joyas de determinado peso, el vestirse con atuendos de colores o el uso del carro para sus traslados por la ciudad. Con ello, se pretendía que las matronas

2 Sobre estos personajes, véanse especialmente Molas 2009 y Cid López 2009, quienes resaltan de qué modo los cambios políticos están ligados a los actos violentos perpetrados contra las mujeres en las etapas más tempranas de la historia de Roma, en concreto bajo la Monarquía y los inicios de la República. Respecto a la trascendencia de sus acciones, véase también Valette 2012.

3 Los hechos atribuidos a estas mujeres y las formas de construir sus biografías han sido objeto de revisiones notables por especialistas de Historia Antigua, ligadas a los estudios de mujeres y de género, quienes resaltan las visiones sesgadas de la historiografía tradicional. Entre otras, destacan las aportaciones de Boëls-Janssen 2008, Cid López 2010b y 2018, Corey Brennan 2012, Rohr Vio 2016 y Valentini 2012.

4 A propósito de estos hechos, sobresale el trabajo pionero de Hemelrijk 1987, enfatizando el significado de estas primeras manifestaciones de las romanas en los aledaños del foro.

5 El contenido de la lex Oppia la menciona solo Tito Livio (34.1). Para mayor información sobre este episodio, en el que se reflexiona también sobre las posiciones enfrentadas de los líderes masculinos y del valor de sus discursos, véase sobre todo Cid López 2010b, 137-143 y nota 40 . 
manifestaran el luto que la calamitosa situación social requería. Finalizado el conflicto bélico y tras la victoria de Roma, la riqueza llegó en elevadas cantidades y benefició también, incluso especialmente, a las mujeres. En estas nuevas circunstancias, las matronas ricas también querían acabar con el duelo, a la vez que mostrar su posición social y el lujo del que disfrutaban. Sus quejas las expuso el tribuno de la plebe Lucio Valerio Máximo, junto a Marco Fundanio, quien debió enfrentarse al tradicionalista Catón; este se opuso firmemente a la retirada de una ley que defendía el viejo orden social y el papel de la matrona a la antigua usanza. Al final, el conocido censor no ganó en esta contienda, pero fue capaz de imponer la lex Voconia en el año 169 a.C., con el único afán de intentar frenar la acumulación de riqueza en manos de las mujeres ${ }^{6}$.

Hubo otra ocasión para la protesta femenina. Sucedió en el año 42 a.C., cuando una vez más las matronas más ricas protestaron por la promulgación de una ley que gravaba las fortunas de las mil cuatrocientas mujeres de mayor patrimonio en Roma. En esta ocasión, Hortensia tomó la palabra en los rostra y consiguió convencer a los dirigentes de turno, presionados sin duda por la acción popular, y la ley se reformó ${ }^{7}$. Solo contribuirían las cuatrocientas mujeres de mayor fortuna. Esta Hortensia era hija de un famoso orador, que por cierto nuestro Ettore Ciccotti conocía bien, al haber sido el defensor de Verres, personaje que fue objeto de su atención en una de sus más difundidas investigaciones ${ }^{8}$.

Ha de señalarse que quizá como manifestación de la ruptura de la domesticidad que había caracterizado a la matrona tradicional, es muy conocido el caso del culto a Baco en sus vertientes más heterodoxas. Procedente de ciudades griegas, en Roma la devoción báquica asumió los elementos más disgregadores del orden social, tales como nocturnidad, consumo de alcohol, bailes desenfrenados, relaciones sexuales fuera de la norma y del matrimonio, y quizá muy especialmente la mezcla de géneros, entre otros. Se trataba de las famosas Bacanales, narradas con detalle por Tito Livio (39. 8-18) ${ }^{9}$. Tal episodio conmocionó a la sociedad romana y se culpabilizó a las mujeres de las transformaciones de este culto en un fenómeno que atentaba contra el buen orden religioso y social; también se las acusó de corromper a los parientes masculinos de su familia, al iniciarlos en este ritual báquico bajo la forma más opuesta a la ortodoxia religiosa imperante. Los nombres de Pacula Ania, la sacerdotisa que introdujo los cambios en el culto, y Duronia, la madre que intentó corromper a su hijo, contrastan con los de la fiel liberta Hispala y las respetables matronas Ebutia o Postumia. Para frenar tales comportamientos femeninos, entre otras razones, y, como castigo ejemplarizante, se aplicó la pena capital a las mujeres seguidoras de este culto, al igual que a los varones. En este episodio, que conmocionó a la sociedad romana, el protagonismo femenino resulta evidente, tanto en el caso de las instigadoras y promotoras como en lo relacionado con las salvadoras. Como era de esperar, fueron Postumio, el cónsul del momento, y el Senado quienes finalmente

6 Con esta ley se intentaba limitar la cantidad a heredar por una mujer, pero parece que se burló con frecuencia. Marcus Iunius Brutus y Publius Iunius Brutus fueron los tribunos de la plebe que la impulsaron, animados por Catón el Censor (Cid López 2010b, 142; Mastrorosa 2006).

7 La emblemática figura de Hortensia, como única oradora conocida en Roma, ha sido analizada, entre otros por Boatwright 2011, 105-141, Cid López 2015, 198-202, Cluett 1998, Lucchelli \& Rohr Vio 2016 o Manzo 2016. Y su discurso figura en Apiano ( $B C, 32$ y 33).
8 Se trata de $I l$ proceso di Verre: un capitolo di storia romana, Milano, 1895, obra que se publicó el mismo ańo que su estudio sobre las mujeres romanas (Ciccotti 1895 a y 1895 b).

9 La bibliografía sobre este episodio que supera el ámbito religioso es muy abundante. Para una valoración del alcance de la presencia femenina y de la construcción de los estereotipos de género, véase Cid López 2007, quien el analiza el texto de Tito Livio (39. 8-18) y el senatus consultum (CIL I 581), así como los debates historiográficos sobre el trasfondo del culto báquico en la Roma del 186 a.C. 
tomaron las riendas y sofocaron lo que fue considerado una conjura contra el Estado (Cid López $2007,135$ y $145-148)$.

Junto a estos episodios e insertos en los dos últimos siglos de la República, se observa el protagonismo creciente de las mujeres de la aristocracia romana en los acontecimientos de la esfera pública. En concreto, no puede perderse de vista la influencia política de las mujeres desde la propia domus, convertida en lugar de conspiración, en connivencia con sus parientes masculinos, maridos o amantes ${ }^{10}$. Parece que era la única vía de participación política femenina y, en realidad, la tolerada por los círculos masculinos del momento. En cualquier caso, la intromisión en una tarea propia de varones no podía estar bien vista. De hecho, tales actitudes disgustaron a los antiguos griegos y romanos — aunque les beneficiara para sus intereses políticos-, como se desprende de sus relatos, y ocurrió lo mismo con autores contemporáneos. Las esposas y el círculo femenino que están presentes en los episodios más criticados de la vida de Mario o Sila, del proceso de Verres, de la conjuración de Catilina, del complot urdido para asesinar a César o de las luchas entre los protagonistas del segundo triunvirato, están también presididos por nombres femeninos como Aurelia Orestila, Sulpicia, Terentia, Servilia o Fulvia, entre otros $^{11}$. Sin olvidar los retratos femeninos que nos dejó Cicerón en su obra pro Caelio, cuando se refiere a la frivola y casquivana Clodia con el afán de atacar a su hermano Clodio, rival político del orador; en este caso, la defensa de Celio Rufo, quien había sido acusado de robar, entre otros delitos, por la propia Clodia, tuvo éxito y Cicerón consiguió exculparlo ${ }^{12}$. $\mathrm{O}$ el alegato de Hortensia, transmitido por Apiano ( $B C, 31$ y 32), supuestamente pronunciado en los rostra, en el que arremete contra la Guerra Civil que de nuevo dividía a la sociedad romana en el año 42 a.C. ${ }^{13}$ En realidad, llama la atención que en las biografías de políticos notables del último siglo de la República, implicados como causantes o víctimas de acciones desestabilizadoras de la res publica, estos hombres notables aparecen siempre acompañados de un pariente femenino, sobre todo la esposa, a veces la amante, con la que comparten idearios políticos y que ha participado en las acciones conspirativas.

Como contrapunto a las acciones de mujeres que se interesan e involucran en los asuntos de la res publica, también aparecen aquellas respetuosas con la tradición, precisamente porque no han roto ni con la sumisión ni con la domesticidad que les exigía la sociedad de su tiempo. De forma paradójica, el caso más notable fue el de Cornelia, la madre de los Graco, que representó el excelso modelo de la matrona; en apariencia no se inmiscuyó en los asuntos políticos, pero sin duda fue ella la que promovió la carrera de sus hijos, y posiblemente también compartía sus programas de

10 Cid López 2018 enfatiza el papel de la domus como espacio femenino para promover la participación en los asuntos de la res publica.

11 Desde su visión tradicional de la República romana, cuya crisis percibía a través de las luchas de las familias dirigentes, el propio Syme 1989 destacaba la importancia de estas mujeres. El hecho de su mención por los autores grecolatinos y la importancia de reconocer sus acciones han sido enfatizadas por Posadas 2011 a propósito de la obra de Salustio, entre otros de sus trabajos. Sobre el protagonismo de estas matronas y su influencia política a fines de la República, destacan las aportaciones de Cid López 2018, sobre todo 615-616, n. 17, y especialmente de Rohr Vio 2016 y 2019, entre otras. Estas figuras casi nunca son bien tratadas en la literatura de la Roma antigua, como se evidencia en el comportamiento atribuido a Servilia por Apiano $(B C$, 2. 112), entre otros casos.

12 Sobre la imagen de Clodia construida por Cicerón en pro Caelio, véase Cid López 2005, sobre todo 177, 180, 198.

13 Para el caso de Hortensia, cuya defensa, sin duda, se explica por su relación de parentesco con Servilia y Bruto, el cesaricida, véase Cid López 2015, 198-213. 
reformas, que marcaron las últimas décadas del siglo II a.C. ${ }^{14} \mathrm{Y}$ al final de la República, destacan Marcia, la fiel esposa de Catón el Joven, y su hija Porcia, casada con Bruto, el cesaricida. Cuando a esta última le notifican la derrota en Filipos, sorprendió a sus contemporáneos por su fidelidad suprema al marido, con quien compartió la muerte, eligiendo tragar carbones incandescentes ${ }^{15}$.

Las acciones de estas mujeres ponen de manifiesto cambios en la sociedad romana, que implican rupturas, al menos en la élite dirigente, de los modelos tradicionales de la matrona. El mero hecho de que sus nombres se conozcan y de que interesen sus acciones a los historiadores de la época revela el alcance de su protagonismo en la sociedad romana ${ }^{16}$. Las aristócratas se interesaron por los asuntos de la res publica y no ocultaron su afán por implicarse en su gestión; lo hicieron en los espacios que se les permitió, casi siempre en la domus, convertida en un centro de conspiración, donde las acciones femeninas debieron alcanzar mayor trascendencia. Rara vez superaron los muros de los espacios domésticos, ya que, tras las protestas para la derogación de la lex Oppia en el 196 a.C., solo se alude a una reivindicación femenina pública cuando se resalta el discurso de Hortensia, del año 42 a.C. ${ }^{17}$

Ciertamente, tales comportamientos son relevantes y muestran a mujeres con formación política, con capacidad de actuar, pero también imbuidas de un modelo social androcéntrico, que nunca cuestionaron. Las aristócratas se implicaban en la defensa de la res publica, como ciudadanas, pero ayudando a los varones de su familia, promoviendo carreras de amigos y parientes, a la vez que intentando obstaculizar las de sus enemigos. En ningún caso se están planteando cambios legales que impliquen consecución de derechos para la población femenina, salvo en lo que afecta a la defensa de sus intereses económicos o a la visibilidad de su estatus social. Nunca reclamaron acceso a un cargo público, asumiendo que el ejercicio de la tarea política era un privilegio masculino, y no lo cuestionaron. Pero el hecho de reivindicar el control de su patrimonio, de colaborar o de promover las conspiraciones en la domus manifiestan elocuentemente de qué modo habían surgido mujeres que rompieron con la tradición. En cualquier caso, sobre unas y otras, las que resistieron, aceptaron la sumisión o se rebelaron, encontramos referencias en Plutarco sobre la fiel esposa Porcia o la madre ejemplar Cornelia, en Cicerón sobre la libertina Clodia o en Tito Livio sobre las instigadoras de las Bacanales, entre otros autores grecolatinos y personajes femeninos de la República ${ }^{18}$. El hecho de que se las mencione ya es significativo en sí mismo. De tal manera que conviene revisar esta información para recomponer las visiones y testimonios de los autores grecolatinos sobre estos personajes y su influencia sobre los varones protagonistas de sus relatos. En tal empresa, están implicados investigadores e investigadoras desde hace tiempo, si bien con planteamientos muy distintos a los perceptibles en autores como Ettore Ciccotti, a quien sí ha de recono-

\footnotetext{
${ }_{14}$ La emblemática Cornelia, paradigma de la matrona y de la feminidad tradicional, ha sido objeto de variados estudios, destacando la biografía última de Dixon 2007, junto a las aportaciones de Hallett 2004. Petrocelli 2001 o Cid López 2015, 193-198, quienes analizan los testimonios transmitidos sobre todo por Plutarco en las vidas de Tiberio y Graco ( $T G, 1,1-7)$, sin olvidar el debate sobre las cartas en las que recrimina a su hijo Cayo por sus acciones políticas, y que le atribuye Cornelio Nepote (De Vir. Ilus. Fragmenta, 1).

15 Según el relato de Apiano, BC., 4, 136. Sobre Porcia y su contrapunto, Fulvia, véase Cid López 2018,
}

630-637. A propósito de la segunda y de su imagen de mujer terrible, véase Virlouvet 2001.

16 En la obra de E. Ciccotti, precisamente, se dan a conocer estos nombres femeninos y sus acciones, proporcionando una larga lista de personajes femeninos desde la Monarquía hasta llegar a los casos de Octavia y Livia, bajo el Principado (1895a, especialmente 5, 7, 12 y 35$)$.

17 Sobre ambos episodios, incluyendo valoraciones en la historiografía reciente, entre otros, véanse Cid López 2010b, 136 y 144-146; 2015, 198-203 y 2018.

${ }_{18}$ Véanse Plutarco, Brut., 23.6.7 y TG, 1-7; Cicerón, Cael., 6, 16, 21, 30-32 y 51 y Tito Livio, 39. 8. 
cérsele el conocimiento de las biografías femeninas que recoge en su libro a través de los textos grecolatinos (Ciccotti 1895a).

En efecto, todas estas matronas romanas estaban bien identificadas por los eruditos, historiadores e intelectuales del siglo XIX, como sucede con Ettore Ciccotti, dada la importancia del conocimiento del latín y la literatura grecolatina en la educación de las elites de la Europa decimonónica. Suelen interesar más las rebeldes, que de algún modo podían haber servido como predecesoras de lo que hicieron mujeres del siglo xIx, ligadas al feminismo y al socialismo, en lo que parecen haber estado comprometidos destacados intelectuales, que hoy tildaríamos de progresistas, al menos con un pensamiento que rompía con la tradición, sobre todo la defensora del modelo social androcéntrico.

\section{La Europa decimonónica y la percepción de las mujeres de la ANTigüedad. LAS HUELLAS DEL SOCIALISMO Y LOS FEMINISMOS}

Y, ciertamente, las mujeres que reivindican sus derechos, las feministas, son una imagen rupturista del modelo tradicional femenino en el siglo xix. Sin duda, esta centuria, en concreto el ańo 1848, marcó el comienzo del feminismo, por la declaración de la llamada Conferencia de Seneca Falls, que se discutió, preparó y redactó en la ciudad del mismo nombre del Estado de Nueva York ${ }^{19}$. En ella, se hace una larga lista de reivindicaciones de las mujeres para lograr la igualdad que ha marcado la lucha feminista hasta el presente. No por casualidad, las protagonistas de este encuentro en sus orígenes habían iniciado su activismo en el movimiento abolicionista de la esclavitud. Lo ocurrido en la localidad norteamericana se difundió en el resto de Estados de EEUU y sus ecos llegaron a Europa, dando origen al feminismo sufragista ${ }^{20}$.

Muy relevante fue la figura de Anna Maria Mozzoni (1837-1930), una de las feministas italianas más destacadas del momento ${ }^{21}$. Esta milanesa, escritora, preocupada por el acceso de las mujeres al trabajo y la educación o la abolición de la prostitución, no solo sobresalió en el movimiento feminista, a la vez fue una de las fundadoras del Partido Socialista Italiano y desarrolló su actividad en la ciudad de Milán; idénticos planteamientos pareció compartir Anna Kuliscioff, si bien luego rompió con los socialistas ${ }^{22}$. En este sentido, fácilmente pudo moverse en los mismos círculos de Ettore Ciccotti, sobre todo entre los socialistas y simpatizantes, al menos durante la estancia en Milán del autor del Mezzogiorno ${ }^{23}$. Al igual que otras feministas de su tiempo, como las protagonistas de Seneca Falls o muchas europeas, parece que Anna Maria Mozzoni defendió también el voto femenino, claramente adscrito al llamado feminismo sufragista. Es decir, reclamaban el ejercicio de una ciudadanía plena y también en femenino. No parece que una de sus preocupaciones fuese la de conocer el pasado y buscar los orígenes de la situación presente de las mujeres.

Al mismo tiempo, en esta época aflora una corriente nueva de pensamiento, ligada también a movimientos sociales y reivindicativos, el marxismo, que fomentó un feminismo sui generis, el lla-

19 La llamada Conferencia de Seneca Falls del año 1848 se considera el hito que marca el inicio del movimiento feminista de la llamada primera oleada (Beltrán \& Maquieira 2001, 43-46).

${ }^{20}$ En la abundante bibliografía sobre el feminismo decimonónico y los personajes más relevantes, destaca el excelente y riguroso trabajo de Offen 2015, 135356.
21 Offen refiere la labor destacada de esta feminista italiana, informando sobre su actividad en Milán y su proyección europea $(2015,192$, n. 41 y 231).

22 Eva Cantarella menciona también a Cristiana di Belgiojoso y la citada Anna Kuliscioff, como feministas conocidas en la sociedad milanesa, y vinculadas al socialismo, sobre todo la segunda (Cantarella 1985, IX-XI).

23 Así lo afirman Cantarella 1985, XI y Elefante 2014, 293-294 y 296-298. 
mado socialista. Se da la circunstancia de que algunos de sus más destacados pensadores, sí que se preocuparon de la cuestión de la mujer y hablaban del movimiento femenino, al margen de feministas como Clara Zetkin y sobre todo de Alexandra Kollontai, a las que podía sumarse el nombre de la propia Anna María Monzoni, si bien más volcada en el activismo feminista ${ }^{24}$. Lo curioso es que, en este caso, sí hay interés por conocer la posición de hombres y mujeres en el pasado, aunque sus interpretaciones hoy se consideren erróneas, en la mayor parte de sus contenidos.

Así sucede con Friedrich Engels, buen conocedor de la obra de Johan Jacob Bachofen y lector de los textos de Lewis Henry Morgan. Ambos, sobre todo el primero, habían llegado a defender la existencia del igualitarismo social y la preeminencia de la mujer — del matriarcado- en las sociedades primitivas. Tales planteamientos se observan en El Origen de la familia, la propiedad privada y el Estado ${ }^{25}$. Esta obra, a pesar de sus buenos propósitos iniciales, en el fondo, no dejaba a un lado los prejuicios de Bachofen quien consideró el matriarcado como el modelo propio de una sociedad caótica. El orden se impone cuando llega el varón ${ }^{26}$. En realidad, similares concepciones pueden verse en la evolución que plantea Morgan, un claro seguidor de las tesis evolucionistas, tan en boga en este siglo, para quien la civilización está precedida de las fases de salvajismo y barbarie $^{27}$.

De igual modo, la huella de estos autores se percibe en el muy conocido trabajo de August Bebel, La mujer y el socialismo ${ }^{28}$. Ciertamente, no es un alegato feminista, ni siquiera del feminismo socialista, aunque sí le dedica atención en los últimos capítulos. En esta obra, se plantea una evolución de la sociedad desde la prehistoria hasta el siglo XVIII, pero paradójicamente apenas se habla de las mujeres. En la reconstrucción de las sociedades «primitivas» o «antiguas», Bebel procede a una disección de su funcionamiento, sin contar ni destacar lo que hicieron las mujeres. Solo habla de la gens, orígenes y disolución hasta conformar el Estado, sobre todo en Roma, pero no repara en la sumisión femenina.

Esta serie de autores y obras están presentes en las visiones del pasado que marcan a especialistas de Historia Antigua, como el propio Ettore Ciccotti. Si bien, ha de reconocerse que las mujeres de la Antigüedad habían ejercido un notable atractivo entre intelectuales y algunos estudiosos, ya en el siglo XVIII. La obra sobre las mujeres Julio-claudias de Jacques Roergas de Serviez no deja de traducirse, leerse y copiarse ${ }^{29}$; en el fondo, atraían las mujeres poderosas. De estos y de otros personajes femeninos, anteriores en el tiempo, trató Ciccotti, notablemente familiarizado con las aportaciones de los socialistas, con quienes compartía su ideario político, pero también con los trabajos de Morgan y Bachofen; probablemente, aunque no lo cita en su obra, también había leído los rela-

\footnotetext{
24 La oposición entre los llamados feminismo burgués o sufragista y el socialista, aunque suele diferenciarse en la historia del movimiento, en la práctica no era tan evidente, dado que muchas socialistas apoyaron la reivindicación del voto femenino (Beltrán \& Maquieira 2001, 75-126 y, sobre todo, Offen 2015, 246, 249-250, 290, 384 y 390.

25 Para una lectura feminista, o al menos desde la perspectiva de los estudios de mujeres, de los trabajos de F. Engels, y también de A. Bebel, destacan las reflexiones de Offen 2015, 245-252.

26 Bachofen 1987 [1861]. Su visión del matriarcado refleja evidentes posturas androcéntricas, al margen de la dificultad de demostrar su teoría.
}

\footnotetext{
27 La obra de Morgan 1971 [1877] se adscribe claramente a las tesis evolucionistas, darwinistas, tan influyentes en esta centuria.

28 En 1878, A. Bebel publicó una primera versión en alemán como Die Frau in der Vergangenheit, Gegenwart, and Zukunft en 1878. Ya traducida al inglés, se publicó en Londres en 1885. Años después, revisó este texto, que tituló, en la edición inglesa de New York, 1905, Woman under Socialism, precisamente la utilizada para las diferentes traducciones diferentes al castellano. Véanse las valoraciones a propósito de esta obra de Offen 2015, 246-250.

29 Roergas de Serviez 1913 [1718]. Una crítica a estas visiones del ilustrado francés en Cid López 2010.
} 
tos construidos por el ilustrado francés sobre las mujeres de la familia imperial, ya que, en el fondo, acaba compartiendo, o deja traslucir, parecidos prejuicios sobre las actitudes de las mujeres que se salen de la norma.

\section{Matronas romanas y acciones políticas en la versión de Ettore Ciccotti. El testimonio DE DONNE E POLITTCA NEGLI ULTIMI ANNI DELLA REPUBBLICA ROMANA}

Puede resultar extraño que un político, jurista y catedrático de Historia Antigua y Lenguas Clásicas, nacido en Potenza en el año 1863 (Lucania, luego Basilicata) y fallecido en el año 1939, en Roma, eligiese como tema de estudio para uno de sus trabajos a las mujeres de la República romana. En concreto, lo tituló Donne e política nell 'ultimi anni de la Repubblica romana y se publicó en el año 1895, con ocasión de una estancia en Milán que marcó su biografía, ciertamente curiosa $^{30}$.

Este singular personaje, oriundo de la llamada provincia de Basilicata, en el Mezzogiorno italiano, pertenecía a una familia rica e influyente, y estaba dotado de una notable curiosidad intelectual $^{31}$. A lo largo de toda su vida combinó su actividad de jurista y político con la de profesor universitario en Miseno, Roma y Milán, entre otros centros. Fue autor de una amplia bibliografía, que incluye temas muy variados sobre la antigua Roma, en especial trató cuestiones políticas y sociales; igualmente, también le interesaron los problemas de su tiempo, personajes y acontecimientos políticos de la Italia en la que vivió ${ }^{32}$. Además, ejerció como diputado en varias legislaturas (Mazza 1977, XXIV-XXV y XXXIII).

Parece que le marcaron profundamente los años vividos en Milán, ciudad en la que se codeó con socialistas muy involucrados en las luchas sociales, pero también en discusiones teóricas. En realidad su paso por Milán (adonde llegó con 28 años y donde residió desde el año 1891 hasta ser expulsado de su universidad en 1898) solo acentuó sus tendencias, ya presentes en sus años juveniles, a la hora de enfrentarse a la injusticia social ${ }^{33}$. De igual modo, se relacionó con pensadores muy conocidos, entre los que destacan August Bebel; la primera versión de La mujer y el socialismo, publicada en 1878, seguramente pudo inspirar incluso a Ettore Ciccotti. Al margen de las relaciones personales e intelectuales, el autor del Mezzogiorno conocía a la perfección los escritos de los padres fundadores del marxismo ya que tradujo textos fundamentales de Karl Marx y Friedrich Engels, cuya influencia se evidencia en sus obras, en las que trata directamente sobre el socialismo o sobre

\footnotetext{
30 En este mismo año publicó Il proceso di Verre: un capitolo di storia romana (Milano, 1895), uno de sus trabajos más conocidos. La elección del corrupto gobernador de Sicilia como tema de investigación probablemente evidencia sus preocupaciones sobre la situación política del momento, ya que intentó combatir la mala praxis política, lo que le granjeó bastantes problemas y obstáculos en el desarrollo de su carrera, sobre todo académica.

31 Entre otras biografías, destaca la reciente de Pascarelli \& Campanelli 2016, que incluye el listado de las obras publicadas, informando sobre su labor de historiador y también de político y parlamentario. Una breve pero atinada reflexión sobre el conjunto de su obra fi-
}

gura en Mazza 1977, LXVII-LXX. B. Montoya trata también con detalle la biografía de E. Ciccotti en su tesis doctoral $(2011,747-800)$, la versión que hemos utilizado en las referencias de notas, si bien el texto ha sido objeto de publicación (2015).

32 El listado completo de las publicaciones de E. Ciccotti figura en Pascarelli \& Campanelli 2016, 225-238. M. Mazza selecciona y comenta sus aportaciones más interesantes (1977, LXVII-LXX).

${ }^{33}$ La influencia de su estancia en Milán parece que marcó su biografía personal, política e intelectual, como destacan la mayoría de los autores, entre otros Mazza 1977, VI, n. 3; Montoya 2011, 751 y Elefante 2014, 295. 
la sociedad antigua de Roma ${ }^{34}$. En la historia de su vida, casi siempre ligada a posiciones que podemos calificar de progresistas, se menciona su aproximación al fascismo de los primeros momentos, al parecer convencido de que podía ser bueno para Italia y la sociedad. De hecho, desde estos sectores se le propuso como candidato en las elecciones. Cuando empezó a ver los derroteros del movimiento liderado por Mussolini, se alejó y fue muy crítico, lo que le valió, si no la persecución, sí la marginación política y parece que también académica. Cuando murió, el 20 de mayo de 1939, el silencio fue absoluto, síntoma de cómo se le consideraba por parte de los fascistas italianos ${ }^{35}$.

Pero más que el político, que en esta ocasión sí ha de tenerse en cuenta, ha de destacarse su papel como académico e historiador de la Antigüedad. Su cátedra fue avalada por profesores como Ettore Pais o Karl J. Beloch, pero sobre todo destacan su dilatada carrera universitaria y su extensa obra $^{36}$. Era, sin duda, un ávido lector y buen conocedor de las fuentes de las sociedades antiguas, sobre todo de Roma, tanto del Derecho romano, dada su formación de jurista, como de la literatura grecolatina. Su reconocimiento como especialista en Historia Antigua se evidencia en su colaboración en la que se presentaba como obra monumental, en concreto el famoso Dizionario epigrafico di antichitâ romaine, promovido por Ettore de Ruggiero en 1886, que empezó a publicarse en 1995. Esta contribución revela también su prestigio como experto en la Historia de Roma ${ }^{37}$.

En sus investigaciones abordó temáticas tan diversas como la economía, las instituciones, la religión, la guerra, la familia y episodios de la historia de Roma; incluso se interesó por las obras de Virgilio y Horacio ${ }^{38}$. Pero, sin duda, su obra más conocida fue Il tramonto della schiavitú nel mondo antico, que escribió en sus años milaneses, aunque se publicó en Turín, en $1999^{39}$. Este trabajo se ha considerado el primer estudio a gran escala sobre la esclavitud antigua, en el que se detecta la influencia de autores ligados a la antropología o la sociología como Karl Bücher, Max Weber, Oswald Spengler, Lewis Henry Morgan o Edward B. Tylor, pero especialmente de Friedrick Engels, y del propio Karl Marx ${ }^{40}$. Su publicación se inserta en el debate abolicionista del esclavismo que preside la centuria decimonónica, en la que se involucraron muchos intelectuales de la época. Para Ciccotti, el empobrecimiento de la sociedad romana debilitó el modelo esclavista y propició su declive. Y, especialmente, este texto ha sido considerado como una auténtica interpretación marxista del mundo antiguo ${ }^{41}$.

Al margen de la relevancia de su libro Il Tramonto..., como otros autores de su tiempo, en el conjunto de su obra, llama la atención de qué modo los temas que le interesaban en el presente los

34 Según resaltan Mazza 1977, XX y XXIII; 1979, 69, entre otros.

35 De hecho, solo le dedicaron dos necrológicas, por cierto muy breves, a pesar de su notable carrera académica y política. Una de ellas la firmó Santo Mazzarino, pero no hubo ninguna por parte de los grupos fascistas (Pascarelli \& Campanelli 2016, III).

36 Según Momigliano, estos dos historiadores, junto a Gaetano de Sanctis y el propio Ettore Ciccotti han sido los más importantes en el primer tercio del siglo $\mathrm{xx}$ en Italia $(1955,281)$.

37 Mazza 1977, LXVII; Montoya 2011, 752 y Elefante 2014, 295.

38 Para las referencias a sus publicaciones, véase el listado exhaustivo que figura en Pascarelli \& Campanelli 2016, 225-238, citado en la nota 30. Estos autores resaltan la preocupación de E. Ciccotti por buscar las causas de los acontecimientos del pasado, como buen historiador (2016, 30-31).

39 Entre otras reflexiones sobre esta obra, destacan de forma sobresaliente las realizadas por M. Mazza, en la introducción que hizo a la reedición de la obra de Ciccotti 1977, que luego publicó de forma abreviada en la revista Klio (Mazza 1979).

40 En realidad, la influencia de estos autores se evidenciará igualmente en el conjunto de la obra de Ettore Ciccotti, como señalan, entre otros, Mazza 1977, XXIV-XXV y XXXIII; 1979, 59-60, 68-69, 71, Momigliano 1955, 282, Finley 1982, 51-53 y Montoya 2011, 747-763.

41 Montoya 2011, 747, 757 y 763. Este autor añade que en la obra preocupa más el determinismo económico y se insiste menos en la lucha de clases y la dialéctica. 
trasladaba al pasado ${ }^{42}$. En concreto, pareció preocuparle la corrupción política, y de ahí su interés por el proceso a Verres (Ciccotti 1895b). El conocimiento de hechos y personajes de esta época, quizá le sirvió también para abordar el caso de las matronas romanas, que podían estar detrás de las intrigas políticas de fines de la República, destacando los personajes femeninos que participan junto a los varones en la conspiración de Catilina, entre otros episodios que jalonan el último siglo de la República ${ }^{43}$.

Fue precisamente durante su estancia en Milán cuando publicó su trabajo sobre el antiguo y corrupto gobernador de Sicilia, Verres, y en el mismo año de 1895, se edita Donne i política... Una coincidencia que no parece responder a la casualidad (Ciccotti 1895a y 1895b). Por el contexto en el que se sitúan estas obras, más aún la segunda, podía pensarse que Ettore Ciccotti elegía a las aristócratas romanas no solo para reforzar sus visiones sobre la corrupción política sino para reivindicar figuras femeninas, que actúan en la esfera política y que parecían verse incluso como predecesoras de las mujeres que abrazan el feminismo y el socialismo. Sus contactos con August Bebel, sus conocimientos de las obras de Friedrich Engels e incluso su propia responsabilidad política así parecían evidenciarlo; sin olvidar la posibilidad, bastante plausible, de que se hubiera relacionado con feministas como Anna Maria Mozzoni. Pero Donne i política... muestra ciertas contradicciones, y en el fondo no es más que un alegato contra el comportamiento de mujeres que se salen de los moldes convencionales de la tradición, con reflexiones incluso muy curiosas impregnadas de prejuicios androcéntricos, y en nada vinculadas con planteamientos feministas, ni siquiera socialistas; en este sentido, parece admirar la sociedad primitiva de Roma, cuando las mujeres son el centro de la familia y propician la estabilidad, ya que coincidían «los intereses de la patria con los del ciudadano y la familia» (Ciccotti 1895a, 8).

Ha de resaltarse que Donne i política... se publicó por primera vez en el año 1895 y se reeditó en el año 1985, con una presentación, que incluye interesantes reflexiones, de Eva Cantarella ${ }^{44}$. Esta autora proporciona igualmente valiosa información sobre el ambiente de Milán, y de Italia en general, a fines del siglo $\mathrm{XIX}^{45}$. Los años transcurridos desde esta reedición nos permiten también ampliar y matizar las valoraciones de la prestigiosa profesora milanesa, beneficiándonos de las aportaciones de los estudios de género, que estaban aún en una fase incipiente en la década de los ochenta del pasado siglo. En cualquier caso, sus valoración de la obra y las opiniones de Ettore Ciccotti son bastante adecuadas y no han perdido actualidad, cuando indica que este historiador, en realidad, elabora "una historia política y social de Roma», en la que «las mujeres iluminan hechos con protagonistas masculinos»; en cualquier caso, le otorga el mérito de resaltar la endogamia, el énfasis en el papel del Derecho e incluso en la atención a los asuntos del amor, que convierte en tema de interés histórico (Cantarella 1985, XX). ${ }^{46}$ Junto a estas críticas, también es posible añadir valoraciones sobre el protagonismo femenino en determinados hechos que jalonaron la historia de la República

42 Lo que enfatizaron Momigliano 1955, 282 y Mazza 1977, XXXI, entre otros.

${ }^{43}$ E. Ciccotti $(1895 a, 35)$ destaca sobre todo nombres como los de Servilia, amante de César y madre de Bruto, para referirse a la figura de la conspiradora.

${ }^{44}$ Sobresale la enorme producción bibliográfica de E. Ciccotti en su etapa milanesa, entre la que se incluye Donne i política..., que también cita Mazza 1977, LXVIII, aunque no le presta apenas atención. Recientemente, la obra sí ha sido analizada por Maria Elefante 2014, 298 y 301-304, quien reconoce al autor del Mez- zogiorno como socialista, pero no como feminista, si bien valora lo novedoso de este tema en su época y, sobre todo, el hecho de que los testimonios literarios, y no solo los jurídicos, también permiten conocer a las antiguas romanas.

45 Sin duda, había una vida intelectual intensa, con presencia notable de socialistas y feministas, cuyas posturas a veces coincidían Cantarella 1985, VIII-XI y Pascarelli \& Campanelli 2016, 8-11.

46 Cuestiones que igualmente enfatiza Elefante 2014, 300-301 y 304. 
desde la perspectiva del historiador italiano, quien suele distinguir a las matronas en función de un comportamiento que transgrede o acepta las reglas del juego masculino.

Ettore Cicotti inicia su obra con una descripción de la situación de la mujer romana, en la que sobresale su posición de sumisión, de inferioridad respecto al varón, incidiendo en las cuestiones jurídicas, en las que evidencia su profundo conocimiento de la cuestión ${ }^{47}$. Se puede percibir, en este caso, cierta crítica a esa posición desigual de las mujeres, en la que afloraría su ideario socialista, marcado por otras lecturas, o posturas como las que en esa época podía defender Clara Zetkin ${ }^{48}$. Pero muy pronto el libro —muy breve, ya que no alcanza las cincuenta páginas- ofrece una evolución de la sociedad romana de modo que, en realidad, nos cuenta lo ocurrido en Roma, pero apenas menciona a las mujeres de esta sociedad. Cuando estas aparecen, lo hacen como apéndices de los varones, o como prototipos de nobleza o perversión, lo que suele pasar con la mayoría de los personajes femeninos mencionados por Ciccotti. La obra finaliza con breves semblanzas biográficas de algunos personajes, incluyendo a Octavia y Livia, a las que identifica con un modelo femenino singular en términos complacientes con sus biografías. Evidentemente, las mujeres que él menciona son las de la élite, las que podían participar en los círculos políticos dirigentes. A pesar de su brevedad, esta obra recoge nombres de mujeres y episodios, que de forma recurrente han interesado a los especialistas en la antigua Roma, no solo de la historia de las mujeres. Por ello, ha de otorgársele cierto valor a esta aportación del autor italiano, a pesar de que sus versiones de las biografías femeninas y el alcance de sus acciones estén hoy ya bastante superados.

Quizá resultan especialmente llamativas las contradicciones en el pensamiento de Ciccotti, de las que no debió ser consciente, dentro de lo que se podía esperar de un socialista, que también conoció ambientes feministas, a la hora de juzgar determinadas acciones de las mujeres; en el fondo, prevalece su posición de intelectual incapaz de sustraerse a los prejuicios androcéntricos. En efecto, por un lado, alude a la desigualdad femenina, que no admite, en principio. Pero, por otro, también admira la sociedad primitiva romana, marcada por la austeridad, por la domesticidad femenina que se producía en un ambiente de sumisión al varón, ya que no podía ocurrir de otra manera (Ciccotti 1895a, 7-9); en el fondo, las mujeres que trata con consideración y respeto son aquellas que muestran devoción al esposo y no se inmiscuyen en asuntos ajenos a la domus. Por ello, cuando avanza en el tiempo y analiza los efectos de la conquista del Mediterráneo en la sociedad romana, lamenta la degeneración y de qué modo la riqueza excesiva resquebrajó y dio al traste con la armonía que presidía la sociedad rural, idílica, de los primeros tiempos (Ciccotti 1895a, 9). Las mujeres también modifican sus comportamientos rompiendo con las tradiciones, lo que podía implicar el final de su sumisión al varón.

En este contexto, Ciccotti sí valoró, desde mi punto de vista muy correctamente, el nuevo papel de las mujeres a la hora de controlar su patrimonio o la relevancia de los matrimonios y los divorcios. Ciertamente, las alianzas y rupturas políticas estaban a la orden del día y las mujeres eran

47 Aunque también trata las leyendas que rodean las biografías femeninas de personajes de la Monarquía y primeros tiempos de la República (Ciccotti 1895a, 1-11). Su reconocimiento de la sumisión femenina, sobre todo cuando escribe sobre la Monarquía, se enfatiza por Elefante 2014, 293 y 298.

48 Como conocedor del pensamiento marxista, es probable que estuviera familiarizado con la obra y los planteamientos de Clara Zetkin, una de las figuras más notables del feminismo socialista. Este personaje probablemente defendía planteamientos similares a las feministas italianas, también relacionadas con el socialismo, al menos cuando unas y otras reclamaban el derecho al trabajo y el bienestar de la familia, o la infancia, sin olvidar la reivindicación del sufragio para las mujeres (Offen 2015, 245-252). 
útiles herramientas en los juegos políticos en su papel de esposas o divorciadas ${ }^{49}$. El autor italiano insiste en que desde mediados del siglo in a.C. hasta Farsalia, en el año 48 a.C., solo veinte familias controlaron la res publica turnándose en el ejercicio del poder, la mayoría de las veces no de forma amistosa (Ciccotti 1895a, 27). En la permanencia de estas veinte familias, fue fundamental el papel de las mujeres no solo como instrumentos al servicio de sus familias sino como protagonistas en la toma de decisiones en los asuntos que afectaban a sus biografías personales o a las de sus parientes, en especial los hijos y/o las hijas.

Ciccotti reconoce el papel o protagonismo femenino e introduce una justificación, no fácil de admitir, ya que otorga un enorme significado a cuestiones sentimentales, que parecen marcar hechos históricos trascendentes en la historia de Roma. Me refiero a la importancia que concede al amor, que define comportamientos femeninos a la hora de acercarse a los varones y hacer sacrificios por ellos; en estos casos, actúan siguiendo el mos maiorum, y defienden, a riesgo de su vida, la de sus esposos, sin olvidar otros parientes masculinos. Así ocurrió con Porcia, la romana que se suicida por amor al esposo, Bruto el cesaricida (Ciccotti 1895a, 25 y 35). Pero habitualmente sucede lo contrario, de modo que Ciccotti resalta el comportamiento inadecuado de nobles ciudadanos romanos, manipulados por mujeres de las que estaban enamorados. En este sentido, no es rara la alusión a las donnine facili, que equipara al modelo de la hetaira griega, cuando se refiere a las mujeres manipuladoras como la pitonisa que acompañaba a Mario, la terrible última esposa de Sila, las protagonistas del proceso de Verres o la propia esposa de Cicerón —aunque más bien la considera compañera dominante-, sin olvidar lo ocurrido en la conjuración de Catilina (Ciccotti 1895a, 13 y 19). Para el autor del Mezzogiorno, estos ejemplos son suficientes para afirmar que los hombres - y se refiere a políticos y militares romanos muy poderosos en su tiempo- se habían convertido en "prisioneros de las mujeres" " ${ }^{50}$. En bastantes casos, desde su perspectiva, lo que está ocurriendo es que las mujeres manipulan y traicionan a sus maridos; ciertamente, ellos también lo hacían con sus esposas. En el fondo, según este autor, el amor, que puede calificarse de romántico, «en este ambiente de vida inquieta, incierta, en realidad ficticia, puede decirse que había cambiado de índole y aspecto ${ }^{51}$. En realidad, y al margen de su biografía como diputado socialista, pero sobre todo académico, resulta llamativo que intente explicar episodios que marcaron la crisis de la República no solo a través de las luchas políticas de la clase dirigente, sino también a través de las relaciones amorosas, muchas veces fuera de las convenciones tradicionales.

Lo sorprendente del relato de E. Ciccotti es que a la hora de presentarnos las acciones de estas mujeres y reconstruir sus biografías, en nada se diferencia de un varón lleno de prejuicios contra las mujeres, y especialmente contra las más poderosas; bien porque vivieron con libertad sus relaciones sexuales, o peor aún, porque se entrometieron en los asuntos políticos. Por ello, critica a Clodia, cuyo retrato es una mera reproducción de lo que versionó y transmitió Cicerón ${ }^{52}$; intenta ver a Servilia como la amante fiel de César, cuando es muy discutible, e incluso inaceptable, su lealtad al dictador, ya que la acción de Bruto estuvo marcada sobre todo por el papel de sus parientes pater-

49 Ciccotti 1895a, 9-12 y 29-30; un tema en el que incidió posteriormente Corbier 1987, entre otros.

50 Ciccotti 1895a, 15, 16 y 19. Así ocurrió con el pretor Verres, cuya amante pareció ser quien decidía realmente las sentencias, o Marco Antonio, dominado por una mima en una etapa de su vida, entre otros.

51 Ciccotti 1895a, 15. Por ello, resalta la temática del amor en los poetas latinos como Virgilio, Tibulo, Catulo, Horacio y sobre todo Ovidio (1895a, 13-15).
52 Para Ciccotti, Clodia es víctima de los celos de Cicerón, quien también la ataca para vengarse de su hermano, pero la imagina como mujer frívola (1895a, 30-36). En el fondo, la imagen de Clodia es paradigmático de la construcción de una biografía femenina por parte del famoso orador; se la desprestigia por sus costumbres libertinas, lo que respondía a la estrategia ciceroniana de atacar a su hermano Clodio, como destacan, entre otros, Cid López 2005, Cenerini 2012 o Skinner 2010. 
nos y maternos, en especial de esta Servilia, su progenitora (Ciccotti 1895a, 35); o convierte a Cornelia en el modelo por antonomasia de lo femenino ${ }^{53}$. En las páginas de Donne i politica... no se muestra como un autor identificado con la reivindicación de una libertad e igualdad de las mujeres en el presente, dados los juicios que emite sobre las que tuvieron protagonismo más allá de la domus, o intentaron tenerlo. Por el menosprecio y la crítica a las mujeres autónomas y con interés en los asuntos públicos, Ettore Ciccotti no es el socialista que intentaba parecer, aunque ciertamente no debió de ser un caso excepcional.

Si nos referimos a los hitos de las protestas femeninas, es curioso que apenas preste atención a las reivindicaciones de las matronas para eliminar la lex Oppia. Trata este asunto para resaltar el discurso de Catón, por cierto, claramente opuesto a las pretensiones de estas «rebeldes»; este, al no poder evitar la anulación de la ley, consiguió imponer otra, la conocida lex Voconia, que suponía un claro perjuicio a las mujeres de posición económica desahogada (Ciccotti 1895a, 11, 16 y 20). Con esta nueva norma se intentaba frenar la acumulación de patrimonio en manos femeninas. Del caso de Hortensia, que apenas se menciona, solo destaca que es una buena oradora como lo era su padre (Ciccotti 1895a, 20). Nada se dice del desafío que su actitud supuso ante la política de los triunviros, de Marco Antonio y Augusto, que estaban persiguiendo a varones de su familia, como el propio Bruto.

En el caso del famoso episodio de Bacchanalia, acepta la información de Tito Livio, quien acusó a las mujeres de introducir la superstitio en Roma, marginando la participación masculina. Es cierto que hay una presencia femenina; en concreto de promotoras y devotas, pero también de víctimas y quizá de chivos expiatorios, además de delatoras. En cualquier caso, al igual que en la antigua Roma, considera que las mujeres eran más propensas a estas prácticas y rituales menos ortodoxos. Para los romanos, y como mostraba el episodio del culto báquico, la superstitio era más propia de las mujeres, de carácter más débil que los varones. Según parece, Ciccotti mantenía idéntica opinión ${ }^{54}$.

Y finalmente, como no podía ser de otro modo, en los episodios de conflictos políticos que jalonan la historia de la República, fruto de conspiraciones que se urdían en los ambientes domésticos, están presentes las mujeres con absoluto protagonismo. Y así, por el texto de Ciccotti, desfilan figuras caprichosas, corruptas o ambiciosas como la mujer de Sila, la terrible compañera de Catilina o Fulvia, una de las esposas de Marco Antonio, entre otras (Ciccotti 1985a, 19, 30 y 35).

Ha de señalarse que estas mujeres, junto a las pertenecientes a la familia imperial, fueron las que suscitaron el interés de los historiadores, mucho antes de que se iniciara la llamada historia de las mujeres y siguiendo la estela de Roergas de Serviez, cuya misoginia resulta exacerbada, o del propio Ciccotti, quien ciertamente ofrece versiones más amables pero igualmente críticas de las vidas de las mujeres poderosas ${ }^{55}$. Los datos que proporcionaban, pero sobre todo las imágenes que construyeron de las biografías de estas mujeres y de sus acciones, siguieron determinando la historiografía

53 De Cornelia, Ciccotti alaba también su formación cultural (1895a, 12 y 7 ).

54 Ciccotti también resalta el protagonismo femenino entre las devotas y promotoras del culto báquico en la sociedad romana del 186 a.C. (1895a, 23). Tal culto atrajo sobre todo a las mujeres, por la «debilidad propia de su ánimo», lo que en su momento comentó Dixon 1984. Véase también Cid López 2007.

55 E. Ciccotti considera que las mujeres actuaron como «auténticas políticas» pero que lo hicieron de forma petulante bajo la República (1895a, 7). Sin embargo, cuando se refiere a Octavia, la hermana de Augusto, le atribuye una "bondad angelical» y a Livia la trata con notable consideración, presentándola como la creadora de la dinastía (1895a, 47). Una imagen más reciente de la esposa de Augusto y madre de Tiberio en Hidalgo de la Vega 2012, 30-36 y 60-74, entre otras muchas investigadoras que han tratado su biografía. 
del siglo xx, como se evidencia en las versiones de Claudine Herrmann, que en poco se diferencia de lo que decía Ettore Ciccotti, aunque su obra se publicó en el año $1964^{56}$.

\section{Reflexión final: Ettore Cicotti y Sus JUicios SObre la MUJer desde LA Matrona DE LA ANTIGUa Roma}

De Ciccotti, por su azarosa biografía, sin duda marcada por el compromiso político y la vinculación con el socialismo que preconizaba la igualdad de clase y, diríamos hoy, de género, quizá también por sus conocimientos sobre la sociedad romana, podríamos esperar otro relato de los hechos protagonizados por las matronas del último siglo de la República. Salvo una cierta compasión que parece observarse en las páginas iniciales de la obra y solo a propósito de las primeras romanas, ciertamente en su descripción de la historia de Roma y de la situación femenina en general, las mujeres no salen bien paradas en Donne i politica... Sin embargo, el hecho de situarlas en la historia, de reconocer su participación en asuntos que marcan los cambios políticos de la República es importante. En cierto modo, ello convierte a este historiador en pionero en el tratamiento de las mujeres de la Roma antigua y su inclusión en el relato histórico. Tal vez, su obra la inspiró el ambiente feminista que muy probablemente conoció en sus años milaneses, pero él no es feminista, ni tampoco puede considerarse que su estudio se adelante en décadas a la historia de las mujeres ${ }^{57}$. De forma llamativa, se evidencia una toma de partido desde el momento en que las actitudes y comportamientos de las mujeres romanas suelen ser objeto de críticas en esta versión de Ciccotti, quien no llega a comprender el contexto en el que actúan y sus formas de comportarse, sobre todo cuando se inmiscuyen en asuntos ajenos a los domésticos; es decir, cuando se interesan e involucran en la res publica. Como un hombre incapaz de superar las convenciones sociales de su tiempo, el autor italiano no percibió que, en la Roma de fines de la República, ni ellas quisieron, ni ellos vieron peligrar el modelo social androcéntrico; optó por enfatizar las relaciones amorosas que parecían determinar los cambios políticos, interpretación, sin duda, bastante desenfocada.

En definitiva, quizá haya que reconocerle a Ettore Ciccotti el mérito de haber elegido a las matronas republicanas como protagonistas de sus investigaciones, de haberles otorgado reconocimiento y acción en los asuntos de la res publica, de haberse casi compadecido de la posición marginal de las mujeres en la sociedad romana y de resaltar la diversidad en sus comportamientos, pero fue un hombre de su tiempo, imbuido de prejuicios patriarcales, que su militancia socialista no suprimió. Dado que no vacila en criticar a Clodia, Sulpicia o Servilia por la exhibición de sus amantes, o por su intromisión en la política, asunto de varones, a la vez que alaba a Turia y Marcia, porque se sacrificaron por sus esposos, así como a Cornelia porque no volvió a casarse para dedicarse a sus hijos, o a las que suicidaban por amor y fidelidad suprema al marido, al que no querían sobrevivir, no hay duda de que el modelo social androcéntrico le seguía gustando. En las últimas páginas de su obra, aunque admira a Livia, la mujer «serena y tranquila», por encima de todo aprecia a Porcia, la esposa que murió porque no podía vivir sin Bruto, el esposo, al que parece entregarse con absoluta devoción (Ciccotti 1895a, 47). Quizá Ciccotti no se dio cuenta de que Porcia elegía

56 Herrman 1964, en realidad, ofrece una visión tradicional de las acciones de estas mujeres, si bien su obra, por la información y la galería que presenta de estos personajes fue muy citada en los primeros trabajos sobre las antiguas romanas cuando irrumpe la historia de las mujeres.
57 Sobre estos temas, también reflexiona ampliamente E. Cantarella en la introducción de la obra de Ciccotti 1985, XX-XXI. 
el suicidio, bien porque no le gustaba que la República desapareciera o porque ya no quedaba nadie de su familia que la defendiese, o estuviera en condiciones de hacerlo. Esta elegía una muerte honrosa y se masculinizaba, pero resulta más novelesco decir que lo hizo por amor al marido, un amor hasta la muerte, tan del gusto de nuestro autor, quien nos acaba ofreciendo más un relato literario que un estudio histórico de lo que hicieron las matronas de fines de la República.

\section{BibLIOGRAFÍA}

BACHOFEn, J. J., 1987 (1.a ed. en alemán, 1861), El matriarcado. Una investigación sobre la ginecocracia en el mundo antiguo según su naturaleza religiosa y jurídica, Madrid: Akal.

Bebel, A., 1976 (1..$^{\mathrm{a}}$ ed. en alemán, 1878), La mujer y el socialismo, Madrid: Ayuso.

Beltrán, E., \& V. Maquieira (eds.), 2001, Feminismos. Debates teóricos contemporáneos, Madrid: Alianza.

Bontwright, M. T., 2011, "Women and Gender in the Forum Romanum», Transactions of the American Philological Association 141.1, 105-141.

BoËls-JansSEN, N., 2008, «La vie des matrones romaines à la fin de l'époque républicaine», en: F. Bertholet, A. Bielman Sánchez, R. Frei-Stolba (eds.), Egypte-Grèce-Rome. Les différents visages des femmes antiques, Bern: Peter Lang, 223-264.

Caliri, E., 2019, "Ciccotti e il problema della schiavitù", en A. Alvar Nuño, Historiografía de la esclavitud, Anejos de la Revista de Historiografía, n. ${ }^{\circ}$ 10, Madrid, 349-362.

Cantarella, E. 1985, «Nota di lettura» a E. Ciccotti (1985, reimpr. de 1895), Donne e politica negli ultimi anni della Repubblica romana, Napoli: Jovene, VII-XXI.

Cenerini, F., 2012, «Sessualità e Imperium: la trasgressione femminile alla fine dell'età republicana», Lectora $18,99-111$.

Cicсотті, E., 1895a (reimpr. en 1985), Donne e politica negli ultimi anni della Repubblica romana, Napoli: Jovene.

Cicсотті, E., 1895b, Il proceso di Verre: un capitolo di storia romana, Milano.

Cicсотті, E., 1977 (1. a ed., Torino, 1899), Il tramonto della schiavitú nel mondo antico, Roma: La Terza.

Cid López, R. M. a , 2005, "Clodia imaginada por Cicerón. La construcción de la biografía de una libertina», en: A. Pedregal Rodríguez y M. González González, Venus sin espejo. Imágenes de mujeres en la antigüedad clásica y el cristianismo primitivo, Oviedo: KRK, 161-184.

Cid López, R. M.a , 2007, «Desviaciones religiosas y violencia contra las mujeres en la Roma antigua. El episodio de Bacchanalia», en: D. Molars (ed.), Violencia Deliberada. Las raices de la violencia patriarcal, Barcelona: Icaria, 135-150.

Cid López, R. M. a , 2009, «Madres para Roma. Las castas matronas y la res publica», en: R. M.a Cid López (ed.), Madres y Maternidades. Construcciones culturales en la civilización clásica, Oviedo: KRK, 155-184.

Cid López, R. M. a , 2010a, "Mujeres poderosas del Imperio romano en la historiografía moderna. Algunas notas críticas a las visiones de la Ilustración y su influencia», en: C. Fornis, P. López Barja de Quiroga, M. Valdés (coords.), Dialéctica histórica y compromiso social. Homenaje al Profesor Domingo Plácido. II, Madrid: Pórtico, 685-702.

Cid López, R. M. a , 2010b, «Mujeres y actividades políticas en la República. Las matronas rebeldes y sus antecesoras en la Roma antigua», en: A. Domínguez Arranz (ed.), Mujeres en la antigüedad clásica. Género, poder y conflicto, Madrid: Sílex, 125-152.

Cid López, R. M.a , 2015, «Las silenciosas mujeres de la Roma antigua. Revisiones desde el género y la historia», en: A. Domínguez Arranz, R. M. a Marina Sáez (eds.), Género y enseñanza de la historia. Silencios y ausencias en la construcción del pasado, Madrid: Sílex, 187-212.

Cid López, R. M.a , 2018, «Mujeres y acción política en la República tardía: las conspiradoras. Imágenes nuevas de viejas prácticas femeninas», en: J. Cortadella, O. Olesti Villa, C. Sierra Martín (eds.), Lo viejo y lo nuevo en las sociedades antiguas, Besançon: Presses Universitaires de Franche-Comte, 619-641. 
Cluett, R. G., 1998, «Roman Women and Triunviral Politics. 43-37 B.C.», Echos du Monde Classique. Classical Views, XII, 17, 17-84.

Corbier, M., 1987, «Les comportements familiaux de l'aristocratie romaine (IIe. siècle avant J.C.-IIIe. siècle après J.C.)", Annales. Economies. Societés. Civilisations, 42, 1267-1285.

Corey Brennan, T., 2012, «Perceptions of Women's Power in the Late Republic: Terentia, Fulvia and the Generation of 63 B.C.E.», en: S. L. James, S. Dillon (eds.), A Companion to Women in the Ancient World, Malden-Oxford-West Sussex: Wiley-Blackwell, 354-366.

Dixon, S., 1984, "Infirmitas sexus: Womanly, weakness in Roman Law», The Legal History Review, Tijdschrift voor Rechtsgeschiedenis, Revue d'histoire du Droit 52. 4, 343-372.

Dixon, S., 2007, Cornelia. Mother of the Gracchi, London-New York: Routledge, 2007.

Elefante, M., 2014, «Ettore Ciccotti, Donne e politica negli ultimi anni della repubblica romana: Un saggio "femminista" del professore "socialista"?», en: S. Cerasuolo, M. L. Chirico, S. Cannavale, C. Pepe, N. Rampazzo (eds.), La tradizione classica e l'Unità d'Italia. Atti del Seminario Napoli (Santa Maria Capua Vetere, 2-4 ottobre 2013), vol. II, Napoli: Satura Editrice, 293-306.

Engels, F., 1975 (1. a ed. en alemán, 1884). El origen de la familia, la propiedad privada y el Estado en Obras escogidas de Marx y Engels. II, Madrid: Fundamentos, 177-345.

Finley, M. I., 1982 (1. a ed. en inglés, 1980), Esclavitud antigua e ideología moderna. Barcelona: Crítica.

Hallett, J. P., 2004, «Matriot Games? Cornelia, Mother of the Gracchi, and the Forging of Family- oriented Political Values», en: F. McHardy, E. Marshall (eds.), Women's Influence on Classical Civilization, London: Routledge, 26-39.

Hemelrijк, E. A., 1987, «Women's Demonstrations in Republican Rome», en: J. Blok, P. Mason (eds.), Sexual Asymmetry.Studies in Ancient Societies, Amsterdam: J. C. Gieben, 217-240.

Herrmann, C., 1964, Le rôle judiciaire et politique des femmes sous la République romaine, Bruxelles: Col. Latomus LXVII.

Hidalgo de la Vega, M. J., 2012, Las emperatrices romanas. Sueños de púrpura y poder oculto, Salamanca: Ediciones Universidad de Salamanca.

Lucchelli, T. M., \& F. Rohr Vio, 2016, «La richezza delle matrone: Ortensia nella dialettica politica al tramonto della repubblica», en: A. Bielman, I. Cogitore, A. Kolb (dirs.), Femmes influentes dans le monde hellénistique et à Rome (III ${ }^{\mathrm{e}}$ siècle avant J.-C.-- ${ }^{\mathrm{er}}$ siècle après J.-C.), Grenoble: Elluc, 175-196.

Manzo, B., 2016, «La parolle alle matrone. Interventi femminili in sedi pubbliche nell età tardo repubblicana", en F. Cenerini, F. Rohr Vio (eds.), Matronae in domo et in re publica agentes. Spazi e occasini dell'azione femminile nel mondo romano tra reppública e primo impero, Atti del Convegno di Venezia, 16-17 ottobre 2014, Trieste: Universitá di Trieste, 121-136.

Mazza, M., 1977, "Introduzione» a E. Ciccotti, Il tramonto della schiavitú nel mondo antico, Roma: La Terza (1. ${ }^{a}$ ed., Torino, 1899), V-LXX.

Mazza, M., 1979, "Tra diritto e storia. "Il tramonto della schiavitú nel mondo antico" di Ettore Ciccotti», Klio 61,1, 57-83.

Mastrorosa, I. G., 2006, «Speeches pro and contra women in Livy 34, 1-7: Catonian Legalism and Gendered Debat», Latomus LXV, 590-561.

Molas i Font, D., 2009, "La maternidad usurpada en las leyendas sobre los orígenes de Roma», en: R. M. ${ }^{\text {a }}$ Cid López (ed.), Madres y maternidades: construcciones culturales de la civilización clásica, Oviedo: KRK, 131-154.

Momigliano, A., 1979 (ed. anas. de 1955) , "Gli Studi Italiani di Storia Greca e Romana dal 1895 al 1939", en Contributo alla Storia degli Studi Classici, Roma: Edizioni di Storia e Letteratura, 275-297.

Montoya Rubio, B., 2011, L'esclavitud en l'Economia antiga: evolució i fonaments de la historiografia moderna. Tesis doctoral leída en la Universidad de Alicante [https://rua.ua.es/dspace/ bitstream/10045/23656/1/Tesi_Montoya.pdf].

Montoya Rubio, B., 2015, L'esclavitud en l'economia antiga: Fonaments discursius de la historiografia moderna (segles XV-XVIII), Besançon: Presses universitaires de Franche-Comté, 2015.

Morgan, H. L., 1971 (1. a ed. en inglés, 1877), La sociedad primitiva, Madrid: Ayuso. 
Offen, K., 2015 (1. a ed. en inglés, 2000), Feminismos europeos, 1700-1950. Una historia política, Madrid: Akal.

Pascarelli, G., \& G. Campanelli, 2016, Ettore Ciccotti. Sud e Politica tra realismo e utopia, Potenza: Grenelle.

Petrocelli, C., 2001 (1. a ed. en italiano, 1994), «Cornelia, the Matrona», en: A. Fraschetti (ed.), Roman Women, Chicago: The University Chicago Press, 34-65.

Posadas, J. L., 2011, «Mujeres en Salustio: estudio prosopo-historiográfico», Gerión 29.1, 169-182.

Roergas de Serviez, J., 1913 (1. a ed. en francés, 1718), The Roman Empresses or the History of the Lives and Secret Intrigues of the Wives of the Twelve Caesars, New York: H. S. Nichols (traducción inglesa de la edición francesa).

Rohr Vio, F., 2016, "Matronae nella tarda repubblica: un nuovo profilo al femminile», en: F.Cenerini, F. Rohr Vio (eds.), Matronae in domo et in re publica agentes. Spazi e occasini dell'azione femminile nel mondo romano tra reppública e primo impero. Atti del Convegno di Venezia, 16-17 ottobre 2014, Trieste: Universitá di Trieste, 1-22.

Rohr Vio, F., 2019, Le custodi del potere. Donne e politica alla fine della Repubblica Romana, Roma: Salerno Editrice.

Skinner, M. B., 2010, Clodia Metelli. The Tribune's Sister, Oxford: Oxford University Press.

Syme, R., 1989 (1. a ed. inglesa, 1939), La revolución romana, Madrid: Taurus.

Valentini, A., 2012, Matronae tra novitas e mos maiorum: spazi e modalità dell azione pubblica femminile nella Roma medio republicana, Venezia: InstitutoVeneto di Scienze dell'azione pubblica.

Valette, E., 2012, "Les “discours" de Veturia, Valeria et Hersilia. Les mises en scène de la parole matronale dans la tradition historiographique romaine ", Cahiers "Mondes Anciens", ANHIMA. Anthropologie et Histoire des Mondes Antiques, 3 [http://mondesanciens.revues.org/index782.html].

Virlouvet, C., 2001 (1. a ed. en italiano, Roma-Bari, 1994), «Fulvia, the Woman of Passion», en: A. Fraschetti, Roman Women, Chicago: University of Chicago, 67-68. 